\title{
MicroRNA-328 enhances cellular motility through posttranscriptional regulation of PTPRJ in human hepatocellular carcinoma
}

This article was published in the following Dove Press journal:

OncoTargets and Therapy

28 October 2015

Number of times this article has been viewed

\author{
Xiaoling Luo' \\ Shiyan Yang ${ }^{2}$ \\ Chuanwen Zhou' \\ Feng Pan' \\ Qianjun $\mathrm{Li}^{\prime}$ \\ Shijie Ma' \\ 'Department of Gastroenterology, \\ Huai'an First People's Hospital, \\ Nanjing Medical University, \\ ${ }^{2}$ Department of Gastroenterology, \\ Huai'an Hospital Affiliated to Xuzhou \\ Medical College and Huai'an Second \\ People's Hospital, Huai'an, Jiangsu, \\ People's Republic of China
}

Objective: Interaction between microRNA (miR-328) and PTPRJ (protein tyrosine phosphatase, receptor type, J) has been reported to be responsible for miR-328-dependent increase in epithelial cancer cell proliferation. However, the role of miR-328 and PTPRJ in hepatocellular carcinoma (HCC) remains unclear. The aim of this study was to investigate the clinical significance of miR-328 and/or PTPRJ expression in human HCC and determine their precise biological functions in this malignancy.

Methods: Expression levels of miR-328 and PTPRJ messenger RNA (mRNA) in 100 pairs of HCC and adjacent noncancerous tissues were detected using quantitative real-time reverse transcription polymerase chain reaction. The associations between miR-328 and/or PTPRJ expression and various clinicopathological features of HCC patients were further statistically assessed. Then, the functions of miR-328 and PTPRJ in migration and invasion of two human HCC cell lines were determined by transwell assays.

Results: miR-328 and PTPRJ mRNA expression levels were markedly upregulated and downregulated in HCC tissues, respectively, compared to adjacent noncancerous tissues. Notably, the upregulation of miR-328 in HCC tissues was significantly correlated with the downregulation of PTPRJ mRNA in HCC tissues $(r=-0.362, P=0.01)$. In addition, miR-328-high and/ or PTPRJ-low expression were found to be closely correlated with high Edmondson-Steiner grading (all $P<0.05$ ) and advanced tumor-node-metastasis stage (all $P<0.05$ ). Moreover, the restoration of miR-328 dramatically promoted HCC cell migration and invasion by repressing PTPRJ expression. Interestingly, the loss of PTPRJ expression could significantly attenuate the inhibitory effects of knockdown miR-328 on the migration and invasion of HCC cells.

Conclusion: These findings demonstrated that the dysregulation of miR-328 and PTPRJ may be associated with tumor progression of HCC patients. Functionally, miR-328 may serve as a crucial oncogene and be implicated in the motility of HCC cells at least in part by the suppression of PTPRJ.

Keywords: miR-328, protein tyrosine phosphatase PTPRJ, hepatocellular carcinoma, cancer progression, migration, invasion

\section{Introduction}

Hepatocellular carcinoma (HCC), the most prevalent type of malignant liver cancer, has been recognized as the third leading cause of cancer-associated death worldwide. ${ }^{1}$ Despite recent advances in disease management and treatment, the unfavorable prognosis in HCC patients remains unchanged, with a median survival of most patients of 6-9 months following diagnosis. ${ }^{2}$ Especially, the overall 5-year survival rate of advancedstage HCC patients is less than $5 \%$ because of intra-hepatic metastases, extrahepatic metastases, early invasion into blood vessels, and recurrence. ${ }^{3}$ Growing evidence based
Correspondence: Shijie Ma

Department of Gastroenterology, Huai'an First People's Hospital, Nanjing Medical University, 6 Beijing Road West, Huai'an, Jiangsu 223300, People's Republic of China

Tel +8651780872126

Fax+8651784922412

Email shijiemal23@।26.com 
on molecular profiling of HCC shows that there are a variety of molecular signaling transduction cascades that are involved into the aggressive progression of this malignancy. Therefore, it is of great significance to improve the understanding of the molecular mechanisms responsible for HCC carcinogenesis, invasion, and metastasis in order to identify the deregulated genes and to develop the novel therapeutic strategies.

MicroRNAs (miRNAs), a type of small conserved noncoding RNAs with approximately 17-23 nucleotides in length, function as critical gene regulators via negatively regulating the expression of target genes by translational inhibition or destabilization of messenger RNAs (mRNAs) at a posttranscriptional level. ${ }^{4}$ In recent years, accumulating attention has been paid to the important biological and pathological roles of miRNAs because of their involvement in the regulation of various cellular processes, including cell development, proliferation, differentiation, apoptosis, motility, and cell cycle, which are all closely correlated with carcinogenesis and cancer progression. ${ }^{5,6}$ Hence, it is no surprise to find that the deregulation of miRNAs is implicated in many human cancers and can function as tumor suppressor genes or oncogenes in a tumor-type manner. Especially, recent studies have identified several deregulated miRNAs in HCC tissues or cells, and revealed their roles in HCC carcinogenesis and progression, providing evidence that restoration of the deregulated miRNAs might be considerable therapeutic strategies in HCC treatment. ${ }^{7,8}$

miR-328 has been regarded as a cancer-related miRNA. Accumulating studies suggest that it may play different roles and function as either an oncogene or a tumor suppressor depending on cancer types. ${ }^{9-14}$ In particular, Paduano et $\mathrm{al}^{14}$ experimentally validated the direct regulatory effect of miR-328 on the mRNA levels of PTPRJ (protein tyrosine phosphatase, receptor type, J) via binding on its $3^{\prime}$-UTR in various cancer cells. It has been indicated that the expression of PTPRJ, a ubiquitous receptor-type protein tyrosine phosphatase, is significantly decreased in a vast majority of human epithelial cancers and cancer cell lines. ${ }^{15-19}$ However, the role of miR-328 and PTPRJ in HCC remains unclear. Therefore, we aimed to investigate the clinical significance of miR-328 and/or PTPRJ expression in human HCC and determine their precise biological functions in this malignancy.

\section{Materials and methods}

\section{Patients and tissue samples}

This study was authorized by the Research Ethics Committee of Huai' an First People's Hospital, Huai' an Hospital Affiliated to Xuzhou Medical College, and Huai'an Second People's
Hospital, People's Republic of China. Before collecting tumor specimens for this study, we acquired written informed consent from each enrolled patient. All specimens were handled and made anonymous according to the ethical and legal standards.

A total of $100 \mathrm{HCC}$ patients who underwent hepatectomy at Huai'an First People's Hospital, Huai'an Hospital Affiliated to Xuzhou Medical College, and Huai'an Second People's Hospital from 2012 to 2014 were enrolled in this study. The diagnoses of all patients as having primary HCC were confirmed by at least two pathologists according to their clinicopathological features. None of the patients received any chemotherapy or radiation treatment prior to the surgery. Patients with a combination of another cancer and a history of liver transplantation were excluded from our cohort. The histological differentiation grades were classified according to the Edmondson-Steiner classification system. ${ }^{20}$ Tumor node metastasis (TNM) stages were graded based on the criteria revised by the American Association for the Study of Liver. ${ }^{21}$ All samples were snap-frozen and stored in liquid nitrogen after collection.

\section{Cell culturation and transfection}

Two human HCC cell lines (SMMC-7721 and BEL-7402) were purchased from the cell bank of the Chinese Academy of Sciences. No ethics statement was required from the institutional review board for the use of these cell lines. The cells were cultured in Dulbecco's Modified Eagle's Medium (DMEM) supplemented with 10\% fetal bovine serum (Thermo Fisher Scientific, Waltham, MA, USA), $100 \mathrm{U} / \mathrm{mL}$ of penicillin (Thermo Fisher Scientific) and $100 \mathrm{mg} / \mathrm{mL}$ of streptomycin (Thermo Fisher Scientific) in a humidified atmosphere of 5\% $\mathrm{CO}_{2}$ at $37^{\circ} \mathrm{C}$.

miRNA-328/normal control (NC) mimics, miR-328/NC inhibitors, small interfering RNA (siRNA) against PTPRJ (si-PTPRJ), and a matched control siRNA (si-con) were chemically synthesized by Shanghai GenePharma Company (Shanghai, People's Republic of China). SMMC-7721 and BEL-7402 cells were transfected with miRNAs (100 nM) or siRNAs (50 nM) using Lipofectamine 2000 Transfection Reagent (Thermo Fisher Scientific) according to the manufacturer's protocol.

\section{RNA extraction and quantitative real- time reverse transcription polymerase chain reaction}

Total RNA was isolated using TRIzolTM Reagent (Thermo Fisher Scientific) according to the manufacturers' instructions. Reverse transcription (RT) reactions were performed using 
the Prime-Script RT reagent kit (TaKaRa, Dalian, People's Republic of China). The quantitative polymerase chain reaction (PCR) was performed using a SYBR Premix Ex Taq TM II kit (TaKaRa). For the detection of miR-328 and PTPRJ mRNA expression levels, stem-loop miR-328 was reverse-transcribed and normalized by U6 and GAPDH, respectively. The sequences of the RT and PCR primers were listed as follows: for miR-328, miR-328-RT 5'-GTC GTA TCC AGT GCA GGG TCC GAG GTA TTC G-3', miR-328 forward primer 5'-CTG GCC CTC TCT GCC C-3', miR-328 reverse primer 5'-GTG CAG GGT CCG AGG T-3'; for U6: U6-RT 5'-GTT GGC TCT GGT GCA GGG TCC GAG GTA TTC GCA CCA GAG CCA ACA AAA ATA T-3', U6-forward primer 5'-TTC CTC CGC AAG GAT GAC ACG C-3', U6-reverse primer 5'-GTG CAG GGT CCG AGG T-3'; for PTPRJ: PTPRJ-RT 5'-CAG TAC AGT GAA TGG GAG CAC TGA C-3', PTPRJ forward primer 5'-GGA TCC TCA GAA CCC ATG AA-3', PTPRJ reverse primer 5'-ACC GAC TGT CCA GTG AGA CC-3'; for GAPDH: GAPDH-RT 5'-CCT GAA GCC AGG GGT TCA ATA CCA ACA AAA ATA C-3', GAPDH-forward primer 5'-CAC CAT CTC TCC AGA AGT GGA C-3', GAPDH-reverse primer 5'-GGC GTC ATC AAA GTT CTG CCA AC-3'.

\section{Western blot analysis}

Total proteins were extracted from human HCC cells by using a modified radioimmunoprecipitation assay buffer $(150 \mathrm{mM}$ $\mathrm{NaCl}, 1 \% \mathrm{NP} 240,0.5 \%$ sodium deoxycholate, $0.1 \%$ sodium dodecyl sulfate, $50 \mathrm{mM}$ Tris, $\mathrm{pH}$ 7.4) in the presence of cOmplete, Mini protease inhibitor cocktail (Roche Diagnostics GmbH, Mannheim, Germany). Western blot analysis was performed after the separation of $50 \mu \mathrm{g}$ of proteins on a sodium dodecyl sulfate (SDS)/4\%-20\% polyacrylamide gel (Bio-Rad, Hercules, CA, USA) with conventional methods and an enhanced chemiluminescence detection kit (Amersham, Piscataway, NJ, USA). After that, filters were probed with mouse anti-hPTPRJ 1:100, hamster anti-mouse PTPRJ 1:1,000, and rabbit anti-GAPDH (Sigma-Aldrich Co., St Louis, MO, USA) 1:1,000 plus HRP-conjugated corresponding secondary antibodies at 1:1,000 (Cell Signalling Technologies, Danvers, MA, USA). Signals were visualized with SuperSignal West Pico Chemiluminescent substrate (Thermo Fisher Scientific) by exposure to films.

\section{Cell migration and invasion assay}

The migration and invasion abilities of human HCC cells transfected with miR-328/NC mimic or miR-328/NC inhibitor with or without si-PTPRJ/si-con were tested by migration and invasion assays, respectively, using the 24-well cell migration kit with $8 \mu \mathrm{m}$-pore polycarbonate membrane (Corning Inc, Corning, NY, USA) and the invasion assay kit (BD Bioscience, San Jose, CA, USA), according to the manufacturer's instructions. The number of migrated or invaded cells on the lower side of the membrane was counted at $200 \times$ magnification from ten different fields of each filter.

\section{Statistical analysis}

SPSS software version 11.0 for Windows (SPSS Inc., Chicago, IL, USA) was used to perform all statistical analyses. In this study, all experiments were performed in triplicate. Data are presented as mean \pm standard deviation of one representative experiment. Student's $t$-test was used to evaluate the continuous variables. The chi-square or Fisher's exact tests were used to evaluate the differences in proportion. In all cases, differences were considered statistically significant at $P<0.05$.

\section{Results Upregulation of miR-328 and downregulation of PTPRJ mRNA in human $\mathrm{HCC}$ tissues}

miR-328 (HCC vs noncancerous: $3.03 \pm 0.89$ vs $1.95 \pm 0.82$, $P<0.01$; Figure 1A) and PTPRJ mRNA (HCC vs noncancerous: $2.57 \pm 0.91$ vs $3.93 \pm 0.82, P<0.01$; Figure $1 \mathrm{~B}$ ) expression levels were markedly upregulated and downregulated in HCC tissues, respectively, compared to adjacent noncancerous tissues. Notably, the upregulation of miR-328 in HCC tissues was significantly correlated with the downregulation of PTPRJ mRNA in HCC tissues ( $r=-0.362, P=0.01$; Figure 1C).

\section{Upregulation of miR-328 and/or downregulation of PTPRJ mRNA associate with aggressive progression of patients with HCC}

To determine the associations of miR-328 and/or PTPRJ mRNA expression with various clinicopathological factors, 100 HCC patients were divided into high or low miR-328/ PTPRJ mRNA groups according to the 50th percentile (median) of relative miR-328/PTPRJ mRNA expression, as analyzed with the chi-square test (Table 1). Of 100 HCC patients, 23 (23.0\%) cases were both high expression of miR-328 and PTPRJ, 20 (20.0\%) cases were both low expression of miR-328 and PTPRJ, 32 (32.0\%) cases were miR-328-high and PTPRJ-low expression, and 25 (25.0\%) cases were miR-328-low and PTPRJ-high expression. In addition, miR-328-high and/or PTPRJ-low expression 

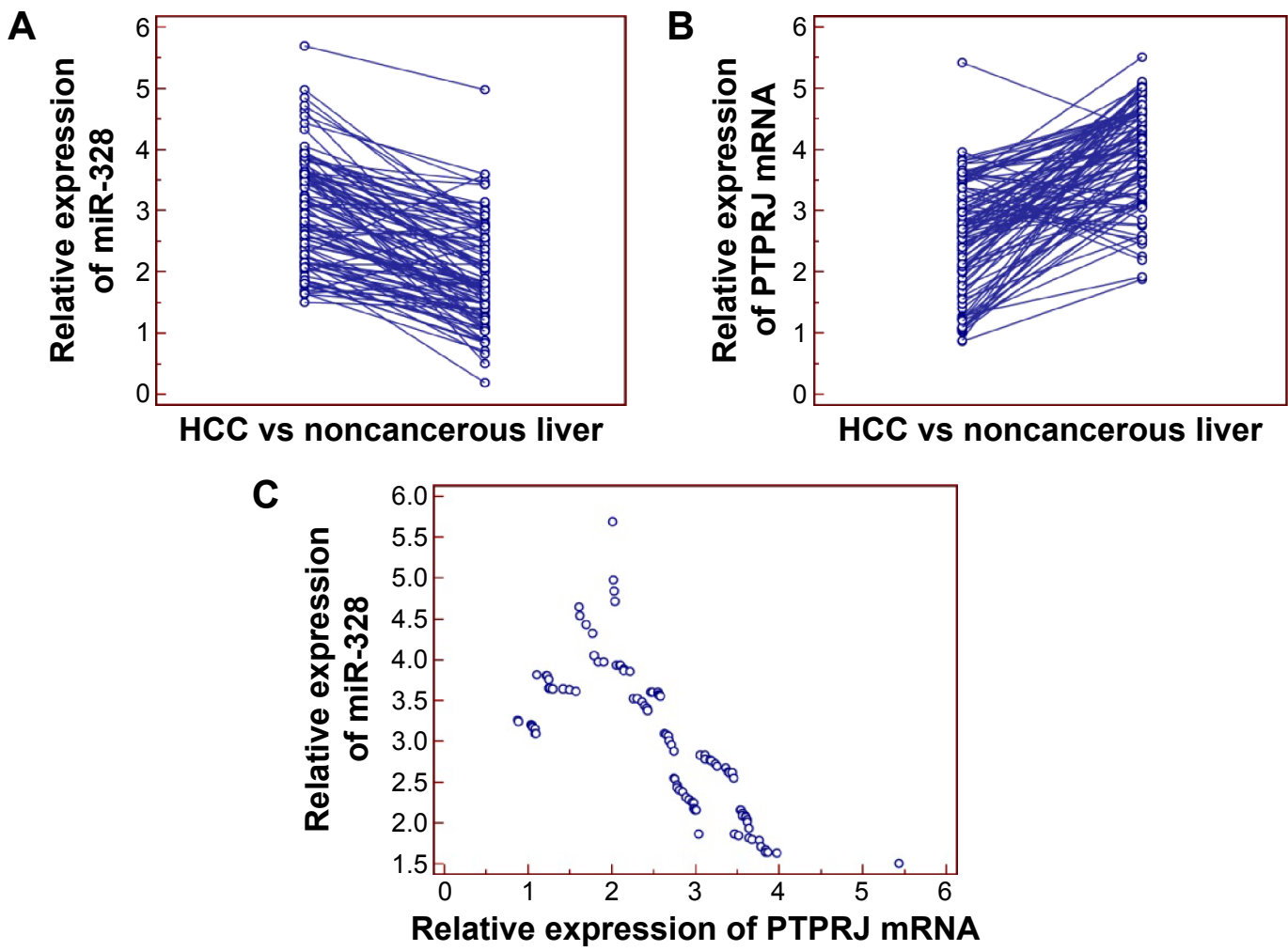

Figure I Upregulation of microRNA (miR)-328 and downregulation of PTPRJ messenger RNA (mRNA) in hepatocellular carcinoma (HCC) tissues. Notes: (A) miR-328 (HCC vs noncancerous: $3.03 \pm 0.89$ vs I.95 $\pm 0.82, P<0.0 \mathrm{I}$ ) expression level was markedly upregulated in $\mathrm{HCC}$ tissues compared to adjacent noncancerous tissues. (B) PTPRJ mRNA ( $\mathrm{HCC}$ vs noncancerous: $2.57 \pm 0.9 \mathrm{I}$ vs $3.93 \pm 0.82, \mathrm{P}<0.0 \mathrm{I}$ ) expression level was markedly downregulated in $\mathrm{HCC}$ tissues compared to adjacent noncancerous tissues. (C) Upregulation of miR-328 in HCC tissues was significantly negatively correlated with the downregulation of PTPRJ mRNA in HCC tissues ( $r=-0.362, P=0.0 \mathrm{I}$ ). Abbreviation: PTPRJ, protein tyrosine phosphatase, receptor type, J.

Table I Association of microRNA (miR)-328 and/or PTPRJ mRNA expression with different clinicopathological features of hepatocellular carcinoma patients

\begin{tabular}{|c|c|c|c|c|c|c|c|}
\hline $\begin{array}{l}\text { Clinicopathological } \\
\text { features }\end{array}$ & $\begin{array}{l}\text { Number of } \\
\text { cases (\%) }\end{array}$ & $\begin{array}{l}\text { miR-328-high } \\
(\mathrm{n}, \%)\end{array}$ & $P$-value & $\begin{array}{l}\text { PTPRJ-low } \\
(\mathrm{n}, \%)\end{array}$ & $P$-value & $\begin{array}{l}\text { miR-328-high/ } \\
\text { PTPRJ-low (n, \%) }\end{array}$ & $P$-value \\
\hline \multicolumn{8}{|l|}{ Age (years) } \\
\hline$<50$ & $42(42.0)$ & $23(54.8)$ & NS & $22(52.3)$ & NS & $15(35.7)$ & NS \\
\hline$\geq 50$ & $58(58.0)$ & $32(55.2)$ & & $30(5 \mathrm{I} .7)$ & & $17(29.3)$ & \\
\hline \multicolumn{8}{|l|}{ Sex } \\
\hline Male & $88(88.0)$ & $48(54.5)$ & NS & $46(52.3)$ & NS & $29(33.0)$ & NS \\
\hline Female & $12(12.0)$ & $7(58.3)$ & & $6(50.0)$ & & $3(25.0)$ & \\
\hline \multicolumn{8}{|l|}{ HBV infection } \\
\hline Negative & $18(18.0)$ & $10(55.6)$ & NS & $9(50.0)$ & NS & $6(33.3)$ & NS \\
\hline Positive & $82(82.0)$ & $45(54.9)$ & & $43(52.4)$ & & $26(31.7)$ & \\
\hline \multicolumn{8}{|l|}{ Serum AFP level (ng/mL) } \\
\hline$<400$ & $25(25.0)$ & $10(40.0)$ & NS & $12(48.0)$ & NS & $6(24.0)$ & NS \\
\hline$\geq 400$ & $75(75.0)$ & $40(53.3)$ & & $40(53.3)$ & & $26(34.7)$ & \\
\hline \multicolumn{8}{|l|}{ Venous infiltration } \\
\hline Negative & $30(30.0)$ & $15(50.0)$ & NS & I5 (50.0) & NS & $10(33.3)$ & NS \\
\hline Positive & $70(70.0)$ & $40(57.1)$ & & 37 (52.9) & & $22(3 \mid .4)$ & \\
\hline \multicolumn{8}{|l|}{ Cirrhosis } \\
\hline Negative & $65(65.0)$ & $35(53.8)$ & NS & $35(53.8)$ & NS & $22(33.8)$ & NS \\
\hline Positive & $35(35.0)$ & $20(57.1)$ & & $17(48.6)$ & & $10(28.6)$ & \\
\hline \multicolumn{8}{|c|}{ Edmondson-Steiner grading } \\
\hline I-II & $72(72.0)$ & $35(48.6)$ & 0.02 & $32(44.4)$ & 0.02 & $17(23.6)$ & 0.01 \\
\hline III-IV & $28(28.0)$ & 20 (7I.4) & & 20 (7I.4) & & 15 (53.6) & \\
\hline \multicolumn{8}{|l|}{ TNM stage } \\
\hline I-II & $70(70.0)$ & $32(45.7)$ & 0.02 & $30(42.9)$ & 0.02 & $12(17.1)$ & 0.01 \\
\hline III-IV & $30(30.0)$ & $23(76.7)$ & & $23(76.7)$ & & $20(66.7)$ & \\
\hline
\end{tabular}

Note: "NS" refers to the difference without statistical significance.

Abbreviations: AFP, alpha fetal protein; HBV, hepatitis B virus; TNM, tumor node metastasis; miR, microRNA; mRNA, messenger RNA. 
were found to be closely correlated with high EdmondsonSteiner grading (all $P<0.05$, Table 1) and advanced TNM stage (all $P<0.05$, Table 1 ).

\section{Upregulation of miR-328 promotes the migration and invasion of HCC cells in vitro}

To determine the functions of miR-328 in the malignant phenotypes of HCC cells, SMMC-7721 and BEL-7402 cells were transfected with miR-328/NC mimics or miR-328/NC inhibitors. As shown in Figure 2, the expression levels of miR-328 in both SMMC-7721 and BEL-7402 cells transfected with miR-328 mimic were substantially increased, compared to those transfected with NC mimic (both $P<0.05$ ).

Then, we found that the enforced expression of miR-328 significantly promoted, but the knockdown of miR-328 dramatically retarded cell migration and invasion of both SMMC7721 and BEL-7402 cells (both $P<0.05$, Figure 3).

\section{Loss of PTPRJ attenuates the inhibitory effects of knockdown miR-328 on the migration and invasion of HCC cells}

To further evaluate the contribution of PTPRJ to functions of miR-328 in the malignant phenotypes of HCC cells, we silenced the expression of PTPRJ protein by RNA interference and confirmed by Western blot normalized to GAPDH. At 48 hours posttransfection, Western blot analysis shown in Figure 4A revealed that the expression level of PTPRJ protein in cells cotransfected with miR-328 inhibitor and si-PTPRJ was significantly lower than that in cells cotransfected with miR-328 inhibitor and si-con. Moreover, the loss of PTPRJ could significantly attenuate the effects of miR-328 inhibitor on cell migration and invasion of both SMMC-7721 and BEL-7402 cells (Figure 4B).

\section{Discussion}

In recent years, the deregulated expression of several miRNAs has been observed in HCC tissues. However, the molecular mechanisms of these miRNAs acting on carcinogenesis and cancer progression have not been fully elucidated. In this study, miR-328 was investigated as a deregulated miRNA in human HCC tissues. Our data confirmed the negative correlation between miR-328 upregulation and PTPRJ downregulation, which has been validated as a target mRNA of miR-328, in HCC tissues. Interestingly, we revealed that miR-328-high and/or PTPRJ-low expression were significantly associated with aggressive progression of human HCC, especially with high Edmondson-Steiner grading and advanced TNM stage. Functionally, this miRNA may act as an onco-miRNA, as it was found to be involved in the development and progression of HCC through suppressing the expression of PTPRJ mRNA. These results not only confirm the promoting effect of miR-328, but also suggest that miR-328 combined with PTPRJ might function as a potential therapeutic target for HCC.

miR-328, together with let-7 $\mathrm{d}^{*}$ and miR18a*, has been reported as one of the multicentric $\mathrm{HCC}$ recurrence-related miRNAs. ${ }^{22}$ Its oncogenic or suppressive role has been confirmed in other types of cancer. MiR-328 may represent a potential diagnostic biomarker of non-small-cell lung cancer, especially for the identification of early-stage tumors. ${ }^{23}$ It may play an important role in maintaining cancer stem-like side population phenotype and may be a potential target for effective colorectal cancer therapy. ${ }^{24}$ miR-328
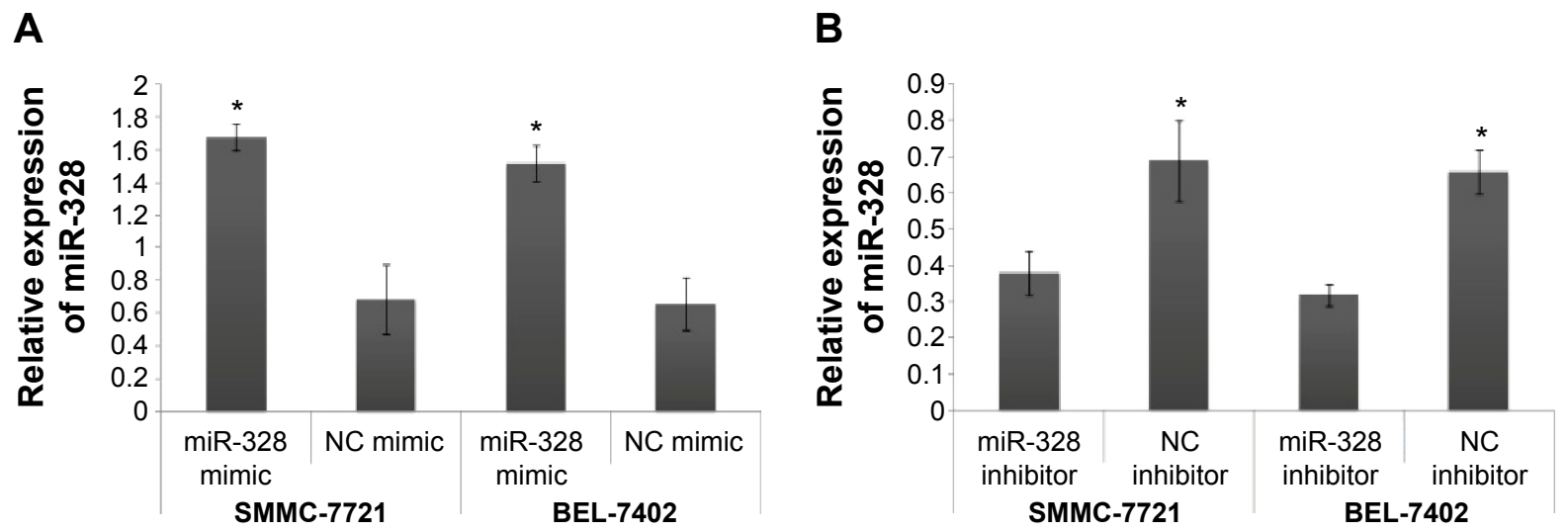

Figure 2 Relative expression of microRNA (miR)-328 in both human hepatocellular carcinoma (HCC) cell lines SMMC-772I and BEL-7402 transfected with miR-328/normal control (NC) mimics and miR-328/NC inhibitors.

Notes: (A) Expression levels of miR-328 in both SMMC-772I and BEL-7402 cells transfected with miR-328 mimic were substantially increased, compared to those transfected with NC mimic $\left({ }^{*} P<0.05\right)$. (B) Expression levels of miR-328 in both SMMC-772I and BEL-7402 cells transfected with miR-328 inhibitor were substantially decreased, compared to those transfected with NC inhibitor $(* P<0.05)$. 
A
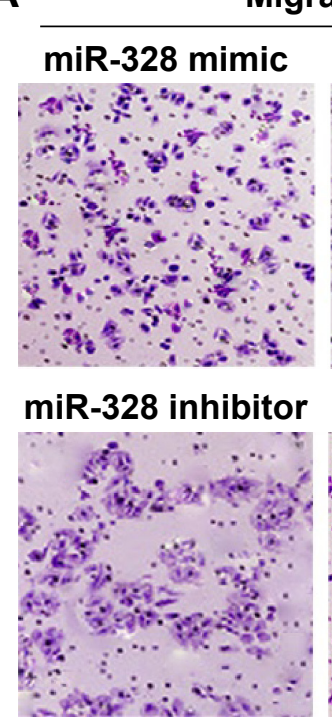

Migration

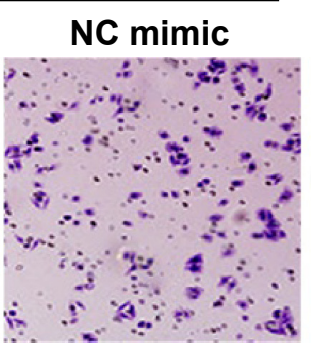

NC inhibitor

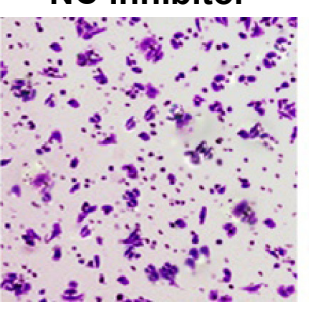

\section{Invasion}

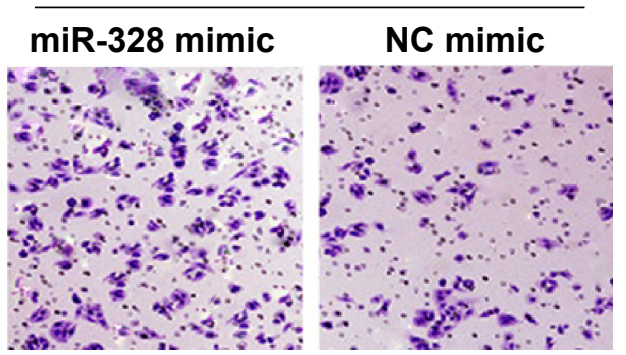

miR-328 inhibitor

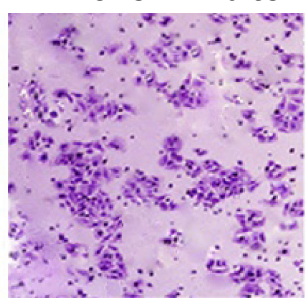

NC inhibitor

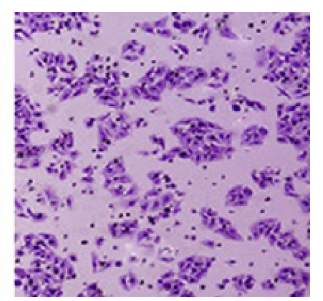

B

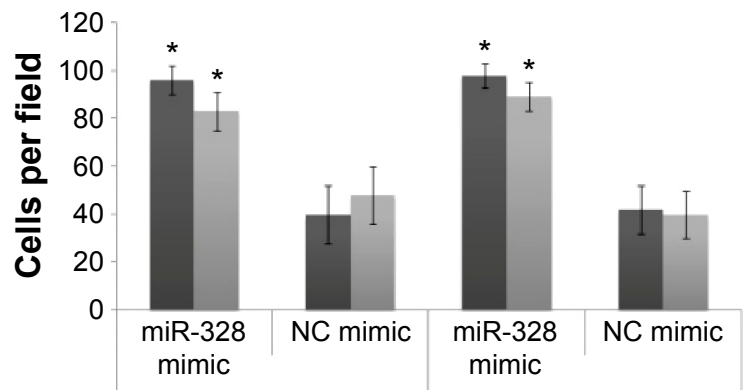

SMMC-7721

BEL-7402

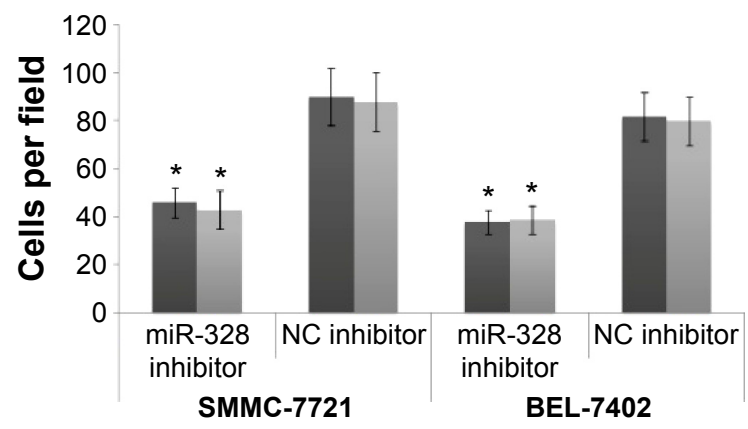

- Migration - Invasion

Figure 3 MicroRNA (miR)-328 promotes the migration and invasion of hepatocellular carcinoma (HCC) cell lines in vitro.

Notes: (A) Representative images showing the migration and invasion abilities of SMMC-772I cells transfected with miR-328/normal control (NC) mimics or miR-328/NC inhibitors. (B) Enforced expression of miR-328 significantly promoted cell migration and invasion of both SMMC-772I and BEL-7402 cells (*P<0.05). Knockdown of miR-328 dramatically retarded cell migration and invasion of both SMMC-772I and BEL-7402 cells $(* P<0.05)$.

could promote glioma cell invasion via SFRP1-dependent Wnt-signaling activation. ${ }^{10}$ Furthermore, macrophages in the tumor microenvironment may cause the increased expression of CD44 via the suppression of miR-328, leading to tumor progression by enhancing reactive oxygen species (ROS) defense; thus, miR-328-CD44 signaling mediated by macrophages might be a potential target for the treatment of gastrointestinal cancer. ${ }^{25}$ In the current study, miR-328 expression was upregulated in $55.0 \%$ of the HCC tissue samples and was positively correlated with tumor progression of HCC patients. Moreover, both the gain-of-function and loss-of-function assays confirmed that miR-328 might function as an oncogene that promoted HCC cell migration and invasion in vitro.

To elucidate the oncogene mechanism of miR-328 in HCC, its target genes were investigated. One such target gene was PTPRJ (also known as DEP-1, CD148, and HPTP), which maps at chromosome $11 \mathrm{p} 11.2$, a region involved in human tumors through loss of heterozygosity, and encodes a receptor-like protein tyrosine phosphatase, the expression of which is strongly reduced in the majority of investigated cancer cell lines and tumor specimens. ${ }^{26,27}$ PTPRJ negatively interferes with intracellular signals mediated by several oncogenic receptor tyrosine kinases. ${ }^{28}$ As a ubiquitous gene, PTPRJ is extensively expressed in all the investigated tissues, including brain, thyroid, liver, spleen, and endothelial cells. Pathologically, the aberrant expression of PTPRJ has been indicated to be able to interfere with cancer cells malignant phenotype both in vitro and in vivo. The binding of PTPRJ interacting peptides to cell cultures could dramatically reduce the extent of both MAPK phosphorylation and total phosphotyrosine levels. Conversely, they could induce a significant 

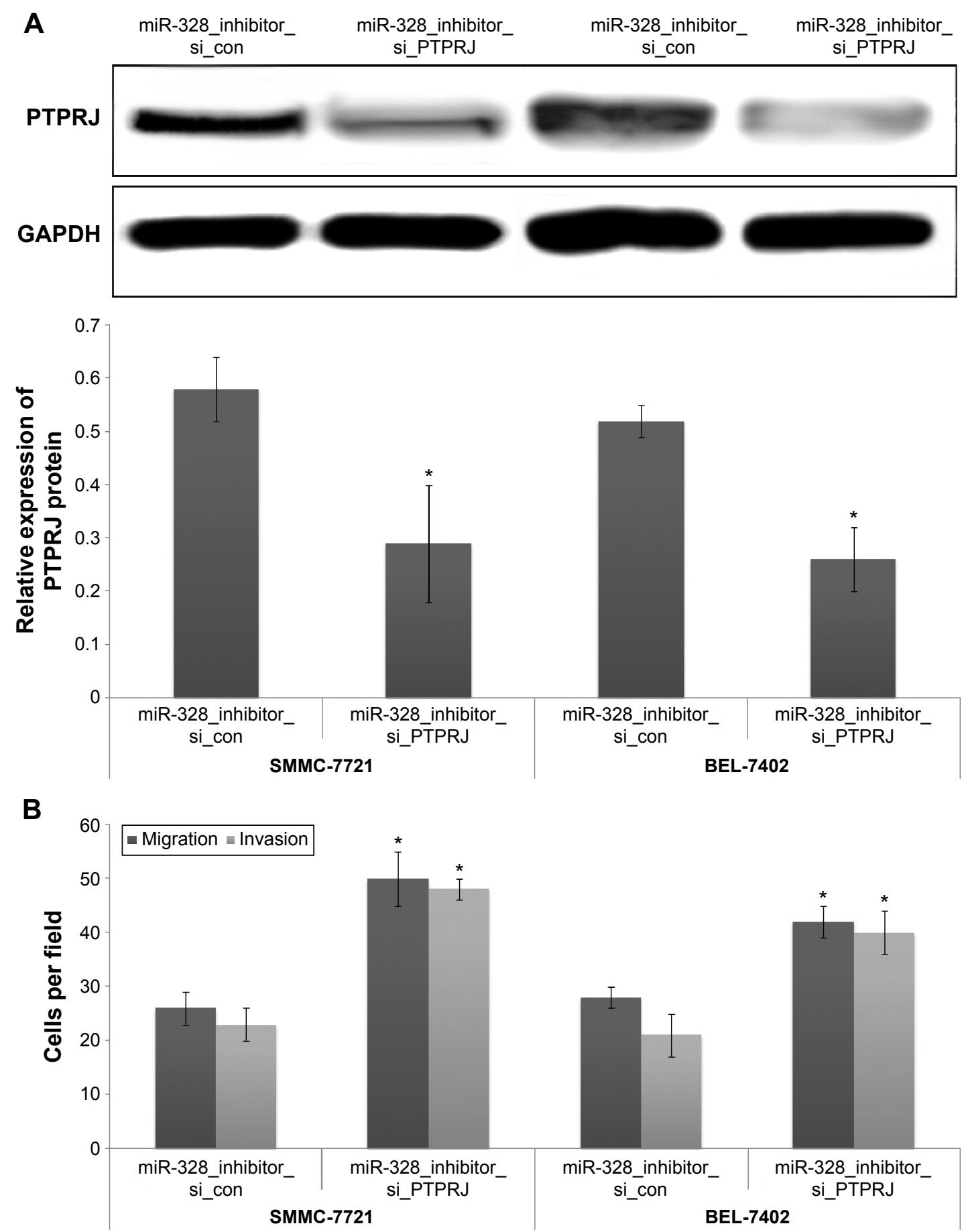

Figure 4 Loss of PTPRJ attenuates the inhibitory effects of knockdown miR-328 on migration and invasion of hepatocellular carcinoma (HCC) cells.

Notes: (A) At 48 hours posttransfection, Western blot analysis revealed that the expression level of PTPRJ protein in cells cotransfected with miR-328 inhibitor and si-PTPRJ was significantly lower than that in cells cotransfected with miR-328 inhibitor and si-con $(* P<0.05)$. (B) Loss of PTPRJ could significantly attenuate the effects of miR-328 inhibitor on cell migration and invasion of both SMMC-772I and BEL-7402 cells $(* P<0.05)$.

Abbreviations: PTPRJ, protein tyrosine phosphatase, receptor type, j; si-con, matched control siRNA; miRNA, microRNA; si, small intefering.

increase in the cell cycle inhibitor p27Kip1. ${ }^{14}$ Moreover, PTPRJ agonist peptides both reduce proliferation and trigger apoptosis of treated cells, suggesting that peptide agonists of PTPRJ positively modulate the PTPRJ activity and may lead to novel targeted anticancer therapies. ${ }^{14} \mathrm{PTPRJ}$ may promote breast cancer cell invasion and metastasis via Src activation. ${ }^{26}$ In particular, the overexpression of miR-328 may decrease PTPRJ expression in various cancer cells and miR-328 acts directly on the 3'-UTR of PTPRJ, leading to the decreased mRNA levels, in line with the results of luciferase assay and 
site-specific mutagenesis, which has identified miR-328 as an important player in the regulation of PTPRJ expression. ${ }^{14}$ Because there are no previous reports on the association of HCC and PTPRJ, quantitative PCR was performed in the current study to detect the expression pattern of PTPRJ in HCC tissues. As a result, we found that PTPRJ expression was decreased in more than half of HCC patients and was negatively correlated with tumor progression. More interestingly, correlation analysis also showed an inverse correlation between miR-328 expression and PTPRJ mRNA expression, and the combined miR-328/PTPRJ expression has more significant associations with clinicopathological features of HCC patients than miR-328 or PTPRJ alone. Furthermore, the functional assay suggests that PTPRJ siRNA could attenuate the inhibitory effects of knockdown miR-328 on the migration and invasion of HCC cells.

\section{Conclusion}

Our findings demonstrated that the dysregulation of miR-328 and PTPRJ may be associated with tumor progression of HCC patients. Functionally, miR-328 may serve as a crucial oncogene and be implicated in the motility of HCC cells at least in part by the suppression of PTPRJ.

\section{Author contributions}

All authors made substantial contributions to conception and design, acquisition of data, or analysis and interpretation of data; took part in either drafting the article or revising it critically for important intellectual content; gave final approval of the version to be published; and agree to be accountable for all aspects of the work in ensuring that questions related to the accuracy or integrity of any part of the work are appropriately investigated and resolved.

\section{Disclosure}

The authors report no conflicts of interest in this work.

\section{References}

1. Bupathi M, Kaseb A, Meric-Bernstam F, Naing A. Hepatocellular carcinoma: where there is unmet need. Mol Oncol. Epub 2015 Jun 25.

2. Attwa MH, El-Etreby SA. Guide for diagnosis and treatment of hepatocellular carcinoma. World J Hepatol. 2015;7:1632-1651.

3. Lacaze L, Scotté M. Surgical treatment of intra hepatic recurrence of hepatocellular carcinoma. World J Hepatol. 2015;7:1755-1760.

4. Shen J, Hung MC. Signaling-mediated regulation of microRNA processing. Cancer Res. 2015;75(5):783-791.

5. Hata A, Lieberman J. Dysregulation of microRNA biogenesis and gene silencing in cancer. Sci Signal. 2015;8:re3.

6. Ibrahim SA, Hassan H, Götte M. MicroRNA regulation of proteoglycan function in cancer. FEBS J. 2014;281:5009-5022.

7. Boye A, Yang Y. Hepatic microRNA orchestra: a new diagnostic, prognostic and theranostic tool for hepatocarcinogenesis. Mini Rev Med Chem. 2014;14:837-852.
8. Gupta P, Cairns MJ, Saksena NK. Regulation of gene expression by microRNA in HCV infection and HCV-mediated hepatocellular carcinoma. Virol J. 2014;11:64.

9. Lee EJ, Baek M, Gusev Y, Brackett DJ, Nuovo GJ, Schmittgen TD. Systematic evaluation of microRNA processing patterns in tissues, cell lines, and tumors. RNA. 2008;14:35-42.

10. Delic S, Lottmann N, Stelzl A, et al. MiR-328 promotes glioma cell invasion via SFRP1-dependent Wnt-signaling activation. Neuro Oncol. 2014;16:179-190.

11. Wu Z, Sun L, Wang H, et al. MiR-328 expression is decreased in high-grade gliomas and is associated with worse survival in primary glioblastoma. PLoS One. 2012;7:e47270.

12. Ishimoto $\mathrm{T}$, Izumi $\mathrm{D}$, Watanabe $\mathrm{M}$, et al. Chronic inflammation with Helicobacter pylori infection is implicated in CD44 overexpression through miR-328 suppression in the gastric mucosa. $J$ Gastroenterol. 2015;50:751-757.

13. Arora S, Ranade AR, Tran NL, et al. MicroRNA-328 is associated with (non-small) cell lung cancer (NSCLC) brain metastasis and mediates NSCLC migration. Int J Cancer. 2011;129:2621-2631.

14. Paduano F, Ortuso F, Campiglia P, et al. Isolation and functional characterization of peptide agonists of PTPRJ, a tyrosine phosphatase receptor endowed with tumor suppressor activity. ACS Chem Biol. 2012;7:1666-1676.

15. Iuliano R, Palmieri D, He H, et al. Role of PTPRJ genotype in papillary thyroid carcinoma risk. Endocr Relat Cancer. 2010;17:1001-1006.

16. Omerovic J, Clague MJ, Prior IA. Phosphatome profiling reveals PTPN2, PTPRJ and PTEN as potent negative regulators of PKB/Akt activation in Ras-mutated cancer cells. Biochem J. 2010;426:65-72.

17. Smart CE, Askarian Amiri ME, Wronski A, et al. Expression and function of the protein tyrosine phosphatase receptor J (PTPRJ) in normal mammary epithelial cells and breast tumors. PLoS One. 2012;7: e40742.

18. Trapasso F, Drusco A, Costinean S, et al. Genetic ablation of Ptprj, a mouse cancer susceptibility gene, results in normal growth and development and does not predispose to spontaneous tumorigenesis. DNA Cell Biol. 2006;25:376-382.

19. Ruivenkamp C, Hermsen M, Postma C, et al. LOH of PTPRJ occurs early in colorectal cancer and is associated with chromosomal loss of 18q12-21. Oncogene. 2003;22:3472-3474.

20. Zhou L, Rui JA, Ye DX, Wang SB, Chen SG, Qu Q. Edmondson-Steiner grading increases the predictive efficiency of TNM staging for longterm survival of patients with hepatocellular carcinoma after curative resection. World J Surg. 2008;32:1748-1756.

21. Bruix J, Sherman M; American Association for the Study of Liver Diseases. Management of hepatocellular carcinoma: an update. Hepatology. 2011;53:1020-1022.

22. Utsunomiya $\mathrm{T}$, Ishikawa $\mathrm{D}$, Asanoma $\mathrm{M}$, et al. Specific miRNA expression profiles of non-tumor liver tissue predict a risk for recurrence of hepatocellular carcinoma. Hepatol Res. 2014;44:631-638.

23. Ulivi P, Foschi G, Mengozzi M, et al. Peripheral blood miR-328 expression as a potential biomarker for the early diagnosis of NSCLC. Int J Mol Sci. 2013;14:10332-10342.

24. Xu XT, Xu Q, Tong JL, et al. MicroRNA expression profiling identifies miR-328 regulates cancer stem cell-like SP cells in colorectal cancer. Br J Cancer. 2012;106:1320-1330.

25. Ishimoto $\mathrm{T}$, Sugihara $\mathrm{H}$, Watanabe $\mathrm{M}$, et al. Macrophage-derived reactive oxygen species suppress miR-328 targeting CD44 in cancer cells and promote redox adaptation. Carcinogenesis. 2014;35:1003-1011.

26. Spring K, Fournier P, Lapointe L, et al. The protein tyrosine phosphatase DEP-1/PTPRJ promotes breast cancer cell invasion and metastasis. Oncogene. Epub 2015 Mar 16.

27. Ortuso F, Paduano F, Carotenuto A, et al. Discovery of PTPRJ agonist peptides that effectively inhibit in vitro cancer cell proliferation and tube formation. ACS Chem Biol. 2013;8:1497-1506.

28. Mita Y, Yasuda Y, Sakai A, et al. Missense polymorphisms of PTPRJ and PTPN13 genes affect susceptibility to a variety of human cancers. J Cancer Res Clin Oncol. 2010;136:249-259. 


\section{Publish your work in this journal}

OncoTargets and Therapy is an international, peer-reviewed, open access journal focusing on the pathological basis of all cancers, potential targets for therapy and treatment protocols employed to improve the management of cancer patients. The journal also focuses on the impact of management programs and new therapeutic agents and protocols on
Dovepress

patient perspectives such as quality of life, adherence and satisfaction. The manuscript management system is completely online and includes a very quick and fair peer-review system, which is all easy to use. Visit http://www.dovepress.com/testimonials.php to read real quotes from published authors.

Submit your manuscript here: http://www.dovepress.com/oncotargets-and-therapy-journal 